\title{
Measurement of Plasma Free Hemoglobin Using Hemolysis Index and Bilirubin Interference
}

\author{
Hanmil Jang ${ }^{1 \oplus}$, Yonggeun $\mathrm{Cho}^{2 \oplus}$, John Hoon Rim ${ }^{1 \oplus}$, Hyein Kang ${ }^{1 \oplus}$, Sang-Guk Lee ${ }^{1 \oplus}$, and \\ Jong-Baeck Lim ${ }^{10}$ \\ ${ }^{1}$ Department of Laboratory Medicine, Yonsei University College of Medicine, Seoul; 2 Department of Laboratory Medicine, Hallim \\ University Sacred Heart Hospital, Anyang, Korea
}

\section{Corresponding author:}

Sang-Guk Lee

Department of Laboratory Medicine, Severance Hospital, Yonsei University College of Medicine, 50-1 Yonsei-ro, Seodaemun-gu, Seoul 03722, Korea Tel +82-2-2228-2455

E-mail comforter6@yuhs.ac

Received: June 8, 2021

Revised: August 25, 2021

Accepted:September 9, 2021
This is an Open Access article distributed under the terms of the Creative Commons Attribution Non-Commercial License (http://creativecommons.org/licenses/ by-nc/4.0) which permits unrestricted non-commercial use, distribution, and reproduction in any medium, provided the original work is properly cited.
Plasma hemoglobin $(\mathrm{pHb})$ is measured when hemolysis is suspected as a result of biochemical, immunological, and mechanical conditions. In this study, we evaluated the clinical feasibility of the hemolysis index (H-index) for $\mathrm{pHb}$ measurement using automated chemistry analyzers. A total of 176 plasma samples were analyzed for $\mathrm{pHb}$ in the Severance Hospital using a Lambda 365 UV/Vis spectrophotometer (PerkinElmer, USA) and Fairbanks method 2. The remnant samples after $\mathrm{pHb}$ measurement were then analyzed for total bilirubin, and $\mathrm{H}$-indices were determined using the automated Atellica CH930 system (Siemens, Germany) and Cobas c702 system (Roche, USA). The equivalence and correlation among the methods were evaluated using Passing-Bablok regression analysis and Spearman's correlation analysis. All the methods showed high correlations with each other. However, the $\mathrm{H}$-indices showed a negative constant bias compared to the Fairbanks method 2. When a cut-off value of $33.2 \mathrm{mg} / \mathrm{dL}$ was applied for diagnosis of hemolysis, 13 samples were determined positive by Fairbanks method 2 but negative by $\mathrm{H}$-indices. These discordant results occurred mostly among samples with total bilirubin levels higher than $3 \mathrm{mg} / \mathrm{dL}$ (12 out of 13 samples). The correlation between total bilirubin and $\mathrm{pHb}$ measured by Fairbanks method 2 showed the largest correlation coefficient $(R=0.347)$ and slope. These results suggest that the pHb measured by Fairbanks method 2 is more prone to bilirubin interference. In summary, our results suggest that $\mathrm{H}$-indices from both automated chemistry analyzers possess excellent clinical feasibility for $\mathrm{pHb}$ measurements and have minimum total bilirubin interference compared to traditional measurement via Fairbanks method 2.

(Lab Med Qual Assur 2021;43:208-13)

Key Words Plasma hemoglobin, Hemolysis index, Spectrophotometry 용혈(hemolysis)은 혈구세포의 세포 내 성분이 세포외액으로 용출되는 현상으로 정의된다[1]. 혈중 혈색소(hemoglobin) 성 분은 일반적으로 적혈구의 세포막 내에 존재하나, 용혈이 일어 나는 경우 세포 외로 유리된 혈색소 성분을 혈장혈색소(plasma hemoglobin) 또는 유리혈색소(free hemoglobin)이라 한다. 용 혈 현상은 생화학적, 면역학적, 물리적, 화학적 기전에 의해 다양 하게 일어날 수 있으며[1,2], 혈장혈색소의 농도 측정은 특히 수혈
부작용[3] 혹은 기계순환[4] 등의 상황에서 혈관 내 용혈의 정도를 모니터링하는 데 유용한 지표가 된다. 혈장혈색소 측정은 또한 용 혈에 의한 검체의 검사 전 오류(pre-analytic error)를 미리 파악 함으로써 검사의 질 관리에 기여하는 역할에서도 그 중요성이 인 정받고 있다[5,6].

전통적으로 혈장혈색소의 측정은 분광광도법(spectrophotometry)을 이용하여 혈색소 고유의 가시광선 영역 흡광대 
역(absorption band)에서의 특정 파장에서의 흡광도(absorbance)를 측정한 후 간섭물질에 대한 특정 파장에서의 흡광도 와 함께 대입한 계산법에 의해 이루어지며, 대표적인 계산법으로 Harboe 방법, Noe 방법, Fairbanks 방법 $1 / 2$ 등이 널리 이용되고 있다[7]. 그러나 혈색소의 흡광대역과 유사한 파장에서 흡광도 변 화가 일어날 경우 혈장혈색소 측정에 간섭이 일어날 수 있으며, 대 표적인 오차원인으로 혼탁도(turbidity)의 증가와 빌리루빈 농도 의 증가가 알려져 있다[5].

용혈 등 비정상 조건에 의한 검사 전 오류를 파악하기 위한 방 법으로, 검체의 용혈/황달/지질혈증 상태를 hemolysis/icterus/ lipemia index (HIL index)로 표현하여 측정 및 보고함으로써 잠 재적 비정상 검체를 자동 검출하는 방법이 임상검사실에서 유용 하게 사용되고 있다. HIL index는 진단적 목적이 아니라 간섭물질 의 탐지를 위하여 사용되는 값으로[8], 별도의 시약없이 자동화학 분석기에서 이중 파장(bichromatic wavelength) 측정치를 이용 한 보정계산을 통해 산출되며, 계산식과 보고방식은 검사장비마 다 개별적으로 설정되어 있다[9]. 이중 파장 측정은 주 파장(main wavelength) 흡광도와 부 파장(secondary wavelength) 흡 광도의 짝을 이용해 계산된다. 세브란스병원 검사실에서 HIL index가 적용된 장비는 Roche사의 Cobas c702 장비(Roche Diagnostics, Indianapolis, IN, USA)와 Siemens사의 Atellica $\mathrm{CH} 930$ 장비(Siemens, Erlangen, Germany)가 있으며, Roche 의 경우 각각 $480 / 505 \mathrm{~nm}$ (황달 영역), $570 / 600 \mathrm{~nm}$ (용혈 영역), $660 / 700 \mathrm{~nm}$ (지질혈증 영역) 세 영역을 측정하며, Siemens의 경 우에도 거의 유사하게 478/505 nm, 571/596 nm, 658/694 nm 세 영역을 측정한다.

용혈 영역에 사용되는 파장은 빌리루빈 흡광도가 증가하는 450-500 nm과 겹치지 않기 때문에, 혈중 빌리루빈 농도에 의한 간섭효과가 낮을 것으로 예측된다. 따라서 H index 산출 시에는 별도의 빌리루빈 측정을 위한 파장은 사용되지 않는다.

본 연구에서는 세브란스병원 검사실에서 사용 중인 Roche사 및 Siemens사의 자동화학분석장비에서 측정된 $\mathrm{H}$ index와 기존 의 분광광도계를 이용하여 측정한 혈장혈색소 간의 일치도를 평가 하고, 추가적으로 혈중 빌리루빈 농도를 함께 측정하여, 각 검사법 에서 측정한 혈중 혈색소 농도와 빌리루빈 농도 간의 상관관계를 분석하여 검사법에 따른 빌리루빈 간섭효과를 평가하고자 하였다.

연구대상은 2018년부터 2019년까지 세브란스병원 본 검사 실에서 혈장혈색소 검사가 의뢰된 검체들을 대상으로 하였다 $(\mathrm{N}=176)$. 검사가 시행되고 남은 잔여 검체를 이용하여, Atellica $\mathrm{CH} 930$ (Siemens)를 이용하여 total bilirubin 값을 측정하 고, Cobas c702 (Roche Diagnostics)와 Atellica CH930 각각 이 보고한 $\mathrm{H}$ index 값을 기록하였다. 또한 기존의 분광광도계
인 Lambda 365UV/Vis Spectrophotometer (PerkinElmer, Waltham, MA, USA)를 이용하여 혈장혈색소 측정에 사용되는 각 파장 영역별 $(415 \mathrm{~nm}, 450 \mathrm{~nm}, 700 \mathrm{~nm})$ 흡광도를 측정하였다. 측정된 흡광도는 다음 계산식에 대입하여 혈장혈색소 농도를 산출 하였다[7,10].

Fairbanks 방법 2

$$
\begin{aligned}
& \mathrm{C}_{\mathrm{Hb}}(\mathrm{mg} / \mathrm{dL})=155.0 \mathrm{~A}_{415}-130.0 \mathrm{~A}_{450}-124.0 \mathrm{~A}_{700} \\
& \mathrm{C}_{\mathrm{Hb}}=\text { 혈장혈색소 농도(hemoglobin concentration), } \\
& \mathrm{Ax}=\mathrm{X} \mathrm{nm} \text { 에서의 흡광도 }
\end{aligned}
$$

Fairbanks 방법 2를 이용해 계산된 혈장혈색소 측정치와, 두 장비가 보고한 $\mathrm{H}$ index 값 간의 일치도를 각각 Passing-Bablok 회귀식을 이용하여 평가하였고, 본 검사실에서 자체 설정한 참고 구간을 기준으로 용혈 여부를 판정한 결과들의 일치도를 kappa value로 평가하였다. 또한 세 가지 측정법의 측정치와 total bilirubin과의 상관성을 Spearman's correlation으로 계산하 였다. 각각의 통계는 Microsoft Office Excel 2016 (Microsoft Corp., Redmond, WA, USA)의 Analyze-it 프로그램을 이용하여 분석하였다. 통계적 유의성은 $P<0.05$ 인 경우를 기준으로 유의하 다고 판단하였다.

Fairbanks 방법 2를 이용해 계산한 혈장혈색소 측정치와 Cobas C702 및 Atellica CH930 의 H index 간의 일치도를 상 호 평가한 결과, Cobas C702와 Atellica CH930의 H index 간 의 상관성과 일치도는 매우 우수하였다(Fig. 1A, B). Fairbanks 방법 2와 Cobas C702 간의 상관계수는 0.949로 높았고, 회귀 식 기울기의 $95 \%$ 신뢰구간이 1 을 포함하고 있어 우수한 일치도 를 보였다(Passing-Bablok fit: plasma hemoglobin [pHb] Cobas [H index] $=-2.908+1.007$ pHb_Fairbanks2) (Fig. 1C, D). Fairbanks 방법 2와 Atellica CH930 역시 상관계수는 0.950로 우수하였고, 회귀식 기울기의 $95 \%$ 신뢰구간이 1 을 포함하고 있 고 일치도가 우수하였다(Passing-Bablok fit: pHb_Atellica [H index] $=-1.806+0.98$ pHb_Fairbanks2) (Fig. 1E, F). 하지만 difference plot을 통해 Fairbanks 방법 2에서 Cobas c702와 Atellica $\mathrm{CH} 930$ 의 H index에 비해 $20 \%$ 이상 높게 측정되는 검 체들이 일부 관찰되었다.

본 검사실에서는 육안상 용혈이 관찰되지 않은 157 명의 용혈성 질환이 없는 환자 검체로 혈장혈색소 농도를 측정하여, 결과값이 비정규분포함을 확인하였고 비모수적 방법으로 97.5 percentile 에 해당되는 $\mathrm{pHb} \leq 33.2 \mathrm{mg} / \mathrm{dL}$ 를 참고구간으로 자체 설정하 였다. 상기 참고구간을 기준으로, 측정한 값이 $33.2 \mathrm{mg} / \mathrm{dL}$ 을 초 과하는 경우 용혈이 양성인 것으로 판정하였을 때, 전체 176 검 

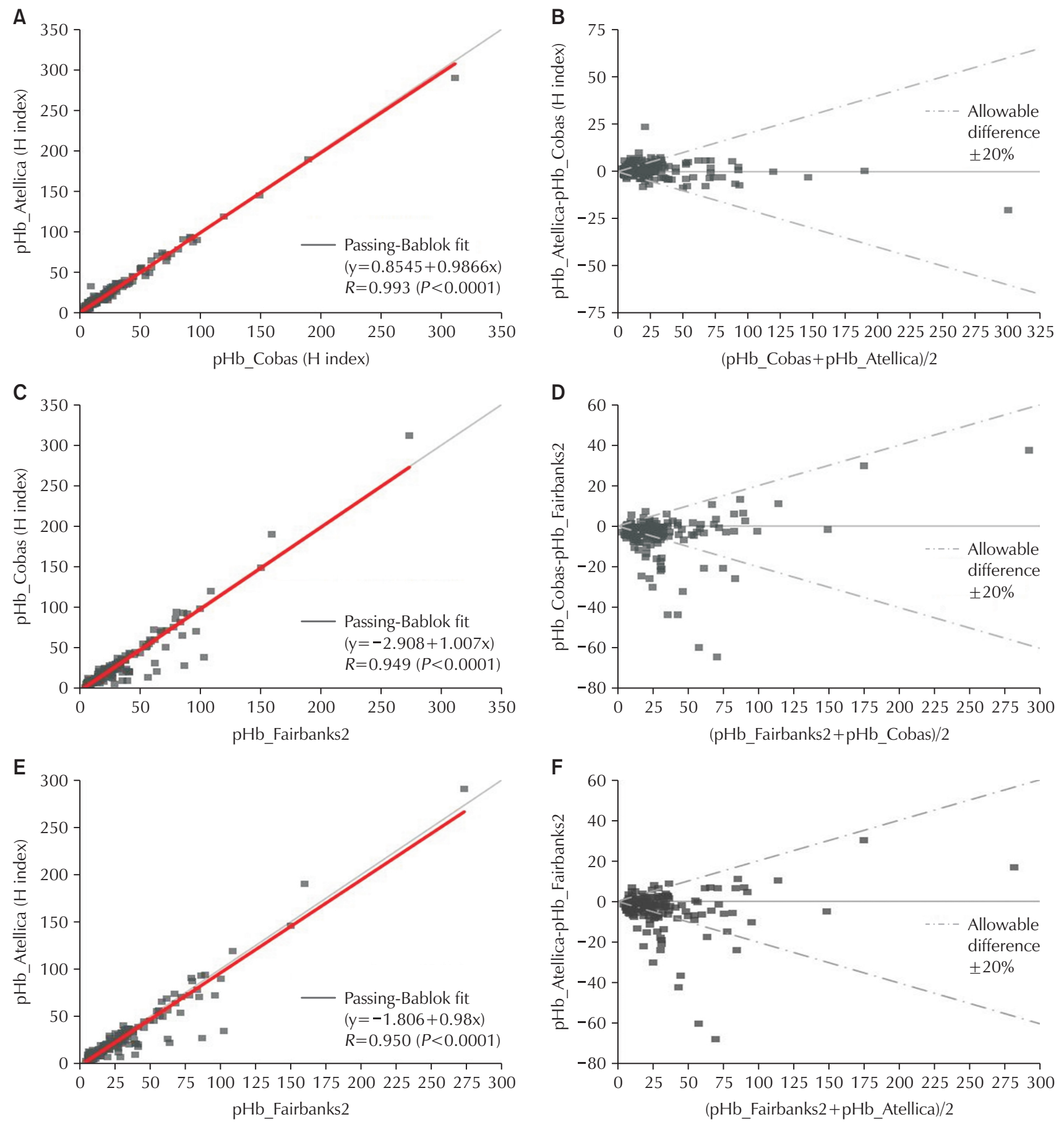

Fig. 1. Method comparison between each measurement via Passing-Bablok analysis. (A, B) Cobas c702 and Atellica CH930 cells: intercept, 0.8545 (95\% confidence interval [Cl], 0.2412 to 1.556); slope, 0.9866 (95\% Cl, 0.9522 to 1.019). (C, D) Fairbanks method 2 and Cobas c702: intercept, -2.908 ( $95 \% \mathrm{Cl},-4.008$ to -1.868 ); slope, 1.007 ( $95 \% \mathrm{Cl}, 0.9595$ to 1.052). (E, F) Fairbanks method 2 and Atellica CH930: intercept, -1.806 ( $95 \% \mathrm{Cl},-2.981$ to -0.5902$)$ ); slope, 0.9800 ( $95 \% \mathrm{Cl}, 0.9282$ to 1.042). The instrument was from the following company: Cobas c702 (Roche Diagnostics, Indianapolis, IN, USA) and Atellica CH930 (Siemens, Erlangen, Germany). Abbreviation: pHb, plasma hemoglobin. 
체 중 용혈이 양성인 것으로 보고한 사례는 각각 53건(Fairbanks 방법 2), 37건(Cobas c702), 42건(Atellica CH930)이었으며, agreement table로 비교한 결과 Cobas c702와 Atellica CH930 간의 일치율 (kappa=0.853)이 Fairbanks 2와 Cobas c702 (kappa $=0.734)$ 간의 일치율, 그리고 Fairbanks 2와 Atellica $\mathrm{CH} 930$ (kappa=0.727) 간의 일치율보다 우수하였다(Table 1). Fairbanks 방법 2의 경우 Cobas c702와 Atellica CH930에서 측 정된 $\mathrm{H}$ index 기준으로는 용혈이 음성인 검체에서 양성으로 판정 되는 경우가 많음을 알 수 있었다. 전체 176 검체 중 Fairbanks 방 법 2상으로는 용혈이 양성이지만 Cobas c702, Atellica CH930 의 $\mathrm{H}$ index상 음성으로 판정한 사례는 각각 15,17 건 발생하였으 며, 두 장비의 $\mathrm{H}$ index가 동시에 음성으로 판정된 사례는 13 건이 었는데, 그 중 12 건이 total bilirubin 농도가 $3 \mathrm{mg} / \mathrm{dL}$ 이상으로 높은 검체였음이 주목할 만한 소견이었다. $\mathrm{H}$ index는 각 자동화 장비별로 상이한 보고방식을 따르지만, 검사실 간 평가결과 용혈 에 의한 부적절 검체 판정에 높은 일치도를 보이는 것으로 알려져 있다[9].

다음으로 빌리루빈과 혈장혈색소 측정값의 연관성을 확인하기 위해 Atellica $\mathrm{CH} 930$ 으로 측정한 total bilirubin 수치와 3가지 방법으로 측정한 혈장혈색소 수치 간의 상관관계를 Spearman's correlation analysis로 분석하였다. 본 연구에서 측정한 176 검 체 중 53건이 시약제조사(Siemens)에서 제시한 total bilirubin 성인 참고구간(0.3-1.2 mg/dL)보다 높은 농도로 측정되었다. Total bilirubin 농도와 Fairbanks 방법 2로 산출된 혈장혈색소 농도의 상관계수와 회귀식 기울기가 total bilirubin과 두 자동화 학분석기에서 산출된 $\mathrm{H}$ index 값과의 상관계수와 회귀식 기울기 보다 높음을 알 수 있었다(Fig. 2). 이를 통해 상대적으로 $\mathrm{H}$ index 가 기존의 Fairbanks 방법 2에 비해 빌리루빈에 의한 간섭으로부 터 자유로움을 확인할 수 있었다.

혈색소는 산화혈색소(oxyhemoglobin), 탈산화혈색소 (deoxyhemoglobin) 및 메트헤모글로빈(methemoglobin) 모
두 공통적으로 $415 \mathrm{~nm}$ 에서 최대 흡광도를 보인다. 두 번째로 높 은 흡광도는 540-580 nm 대역에서 나타나며, 산화혈색소는 $544 / 570 \mathrm{~nm}$ 두 파장에서 흡수극대를 보이나 탈산화혈색소는 $555 \mathrm{~nm}$ 에서 흡수극대를 보이는 차이점이 있다[11]. 혈중 빌리루 빈의 흡광도는 450-500 nm 대역에서 증가하며, 상기 혈장혈색 소 검사법들은 대부분 $415 \mathrm{~nm}$ 파장의 흡광도를 이용하기 때문에 특히 빌리루빈에 의한 간섭을 심하게 받을 수 있다[12].

고빌리루빈혈증 검체에서 혈장혈색소를 측정하는 경우, 450 $\mathrm{nm}$ 근방의 파장대역 흡광도가 과측정되는 경향에 의해 헤모글 로빈의 $415 \mathrm{~nm}$ 파장대역 흡광도가 왜곡됨이 익히 알려져 있다. 2002년의 국내 연구에 따르면, 고빌리루빈혈증에서 혈장혈색소 측정 시 Kahn 방법 $\left(\mathrm{C}_{\mathrm{Hb}} \mathrm{mg} / \mathrm{dL}=155.0 \mathrm{~A}_{578}-86.1 \mathrm{~A}_{562}-68.9 \mathrm{~A}_{598}\right)$ 및 Fairbanks 방법 2가 Harboe 방법 $\left\{\mathrm{C}_{\mathrm{Hb}} \mathrm{mg} / \mathrm{dL}=83.64\left[2 \mathrm{~A}_{415}-\right.\right.$ $\left.\left.\left(\mathrm{A}_{380}+\mathrm{A}_{450}\right)\right]\right\}$ 또는 Noe 방법 $\left(\mathrm{C}_{\mathrm{Hb}} \mathrm{mg} / \mathrm{dL}=165.0 \mathrm{~A}_{415}-93.0 \mathrm{~A}_{380}-\right.$ $73.0 \mathrm{~A}_{470}$ )에 비해 빌리루빈에 의한 간섭이 상대적으로 낮은 양상 을 보였으나[10], 이번 연구에서와 마찬가지로 Fairbanks 방법 2 가 빌리루빈에 의한 간섭으로부터 완전히 자유롭지는 못하였다. 2018년의 다른 비교실험에 따르면, 비황달(non-icteric) 검체와 황달(icteric) 검체들을 구분하여 시행한 정확도 평가결과, 비황달 검체군에서의 부정확도는 큰 변동이 없는 반면, 황달 검체군에서 Harboe, Noe, Fairbanks 방법의 부정확도(inaccuracy)가 각각 $840 \%, 941 \%, 253 \%$ 까지 높아지는 양상을 보였다[13].

이처럼 Fairbanks 방법 2를 포함해 $415 \mathrm{~nm}$ 파장의 흡광도를 사용하는 계산법은 빌리루빈의 영향에 근본적으로 취약하며, 고빌 리루빈혈증의 간섭을 해결하기 위해 bilirubin oxidase를 첨가하 는 방법이 개발되어 있으나[14], 별도의 절차가 필요하므로 검사 실 운영의 효율성과 자동화를 저해하게 된다. 반면에 $\mathrm{H}$ index는 자동화학분석기 간섭물질을 모니터링하기 위해 항시 측정되는 값 으로, 별도의 절차나 소모품이 필요 없다. 따라서 이를 혈장혈색소 측정에 응용할 경우 효율적이고 정확한 검사가 가능하다.

$\mathrm{H}$ index의 임상적 한계점은 유사하게 $415 \mathrm{~nm}$ 파장 영역을 사

Table 1. Hemolysis determination based on the medical decision point ( $\mathrm{pHb} \leq 33.2 \mathrm{mg} / \mathrm{dL}$ )

\begin{tabular}{llrc}
\hline & Negative/positive & \multicolumn{2}{c}{ Fairbanks 2} \\
\cline { 2 - 3 } Cobas c702 (H-index) & Negative $(\leq 33.2 \mathrm{mg} / \mathrm{dL})$ & 122 & 17 \\
& Positive $(>33.2 \mathrm{mg} / \mathrm{dL})$ & 1 & 36 \\
Atellica CH930 (H-index) & Negative $(\leq 33.2 \mathrm{mg} / \mathrm{dL})$ & 119 & 15 \\
& Positive $(>33.2 \mathrm{mg} / \mathrm{dL})$ & 4 & 38 \\
\hline
\end{tabular}

The instrument was from the following company: Cobas c702 (Roche Diagnostics, Indianapolis, IN, USA) and Atellica CH930 (Siemens, Erlangen, Germany).

Abbreviation: pHb, plasma hemoglobin. 
A
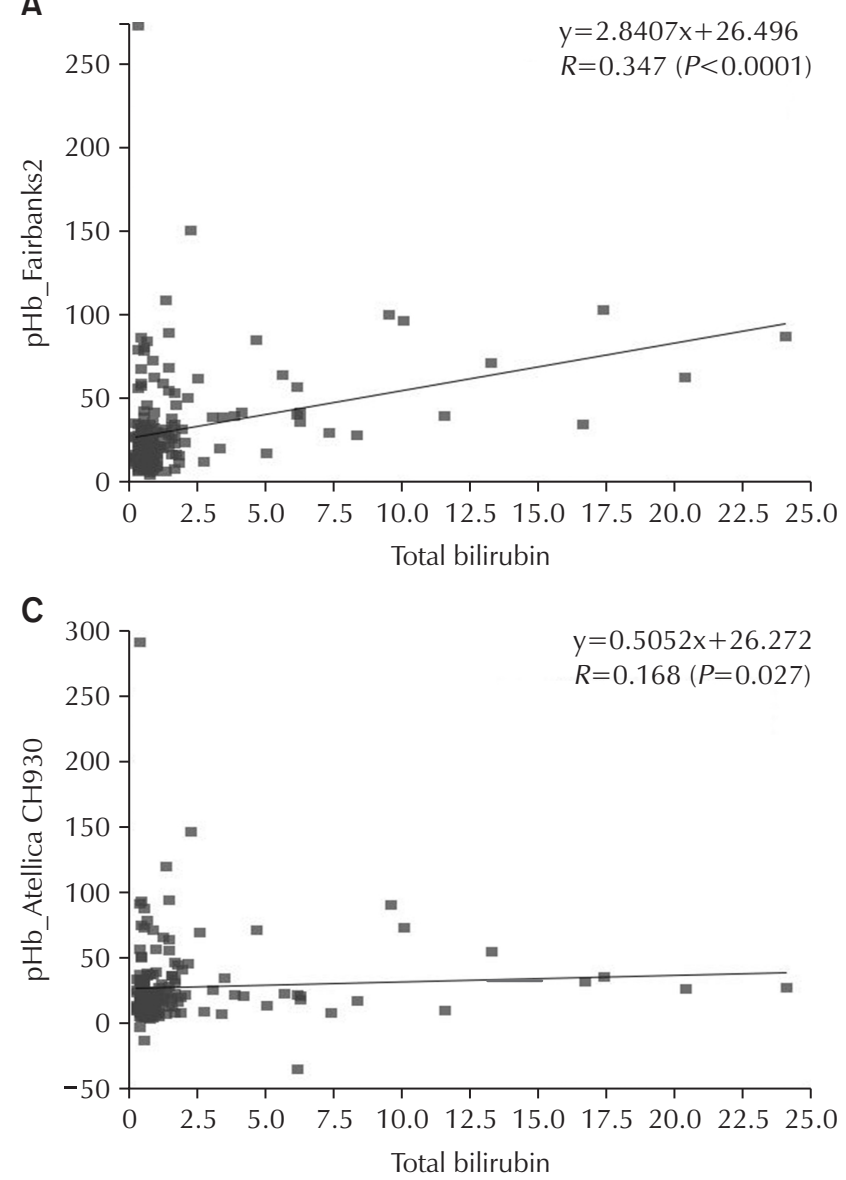

용하지 않는 Kahn 방법의 경우에서 찾아볼 수 있다. Kahn 방법 의 경우 $570 \mathrm{~nm}$ 에서 흡수극대를 보이는 산화혈색소 성분만을 측 정하며, 용혈 시 함께 혈장에 노출되는 다른 형태의 혈색소(메트헤 모글로빈, 메트헴알부민 등)의 양이 매우 높은 경우에는 이를 반영 하지 못한다는 것이 보고되었다[7]. H index 또한 $570 \mathrm{~nm}$ 이상 의 파장만을 이용한 측정법이므로, 메트헤모글로빈, 메트헴알부민 은 측정할 수 없는 단점이 있을 수 있다.

결론적으로, $\mathrm{H}$ index는 황달에 의한 영향이 최소화되는 혈장혈색 소 측정법으로, 기존의 분광광도계 분석과 높은 일치도를 보이면서 도 기존의 방법에 비해 total bilirubin에 의한 간섭이 적어 용혈의 위양성률을 낮출 수 있는 장점이 있었다. 따라서 메트헤모글로빈과

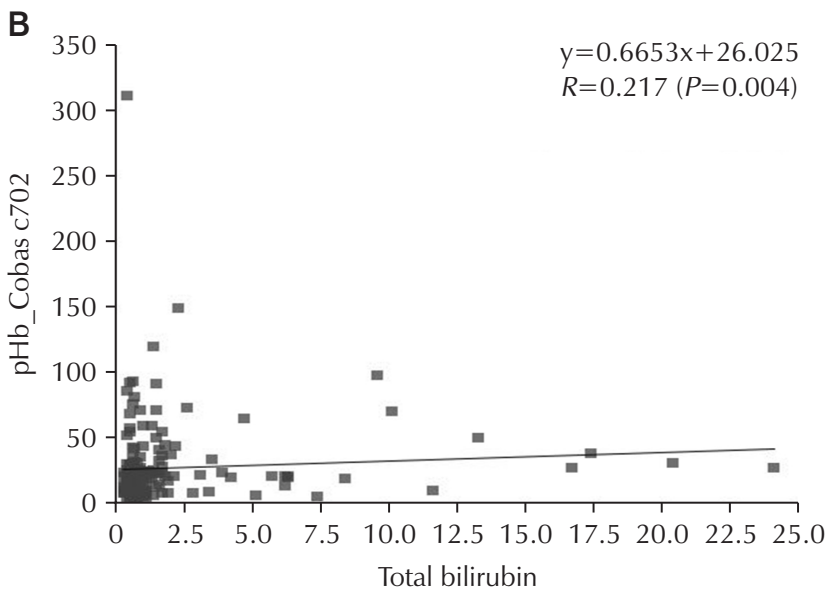

Fig. 2. Spearman's correlation analysis between total bilirubin and each measurement (unit: $\mathrm{mg} / \mathrm{dL}$ ). The instrument was from the following company: Cobas c702 (Roche Diagnostics, Indianapolis, IN, USA) and Atellica CH930 (Siemens, Erlangen, Germany). Abbreviation: pHb, plasma hemoglobin.

같은 다른 형태의 혈색소가 증가되는 경우를 제외하고는 H index가 혈장혈색소를 측정하는 데 유용하게 사용될 수 있을 것이다.

\section{ORCID}

Hanmil Jang

https://orcid.org/0000-0002-2694-7353

Yonggeun Cho https://orcid.org/0000-0003-1946-4318 John Hoon Rim https://orcid.org/0000-0001-6825-8479 Hyein Kang Sang-Guk Lee https://orcid.org/0000-0003-0789-8223 https://orcid.org/0000-0003-3862-3660 Jong-Baeck Lim https://orcid.org/0000-0003-0419-0422

\section{REFERENCES}

1. Thomas L. Haemolysis as influence \& interference factor. EJIFCC 2002;13:95-8.

2. Blank DW, Kroll MH, Ruddel ME, Elin RJ. Hemoglobin interference from in vivo hemolysis. Clin Chem 1985;31:1566-9.

3. Lippi G, Blanckaert N, Bonini P, Green S, Kitchen S, Palicka V, et al. Haemolysis: an overview of the leading cause of 
unsuitable specimens in clinical laboratories. Clin Chem Lab Med 2008;46:764-72.

4. Lubnow M, Philipp A, Foltan M, Bull Enger T, Lunz D, Bein T, et al. Technical complications during veno-venous extracorporeal membrane oxygenation and their relevance predicting a system-exchange: retrospective analysis of 265 cases. PLoS One 2014;9:e112316.

5. Guder WG, da Fonseca-Wollheim F, Heil W, Schmitt YM, Topfer G, Wisser H, et al. The haemolytic, icteric and lipemic sample recommendations regarding their recognition and prevention of clinically relevant interferences: recommendations of the Working Group on Preanalytical Variables of the German Society for Clinical Chemistry and the German Society for Laboratory Medicine. J Lab Med 2000;24:357-64.

6. Carraro P, Servidio G, Plebani M. Hemolyzed specimens: a reason for rejection or a clinical challenge? Clin Chem 2000;46:306-7.

7. Fairbanks VF, Ziesmer SC, O'Brien PC. Methods for measuring plasma hemoglobin in micromolar concentration compared. Clin Chem 1992;38:132-40.

8. Petrova DT, Cocisiu GA, Eberle C, Rhode KH, Brandhorst G, Walson PD, et al. Can the Roche hemolysis index be used for automated determination of cell-free hemoglobin?: a comparison to photometric assays. Clin Biochem 2013;46:1298-301.

9. Lippi G, Luca Salvagno G, Blanckaert N, Giavarina D, Green S, Kitchen S, et al. Multicenter evaluation of the hemolysis index in automated clinical chemistry systems. Clin Chem Lab Med 2009;47:934-9.

10. Park KU, Jung JS, Song J, Kim JQ. Measurement of plasma hemoglobin in hyperbilirubinemia. Korean J Lab Med 2002;22:382-7.

11. Kwon YI. A review of the characteristics of early apparatus and methods for hemoglobin estimation. Korean J Clin Lab Sci 2016;48:401-10.

12. Dolci A, Panteghini M. Harmonization of automated hemolysis index assessment and use: is it possible? Clin Chim Acta 2014;432:38-43.

13. Paal M, Lang A, Hennig G, Buchholtz ML, Sroka R, Vogeser M. A second-derivate fitting algorithm for the quantification of free hemoglobin in human plasma. Clin Biochem 2018:56:62-9.

14. Wong SS, Schenkel OJ. Quantification of plasma hemoglobin in the presence of bilirubin with bilirubin oxidase. Ann Clin Lab Sci 1995;25:247-51. 